\title{
Metaphorical Modeling in Fictional Prose as a Reflection of Its Thematic Focus
}

\author{
Vladimir Andreev \\ PhD (Linguistics), Chair, Department of English, Lev Tolstoy Pedagogical University \\ Tula, Russia; andreev@tspu.tula.ru
}

\section{Zhanna Fomicheva}

PhD (Linguistics), Associate Professor, Department of English, Lev Tolstoy Pedagogical University Tula, Russia; libra@newmail.ru

\section{Doi:10.5901/mjss.2016.v7n3s1p263}

\begin{abstract}
This paper aims to present the results of the study of metaphorical modeling in the contemporary prose in English using the methodology of Cognitive Linguistics which helps to single out the sources and targets of metaphorical modeling in contemporary fiction. The research focuses on such targets and sources of metaphorical modeling as HISTORY, CIVILIZATION, NATURE and HUMAN BEING. The research of this kind helps to uncover the world view presented in the key texts of contemporary fiction in relation to the four basic concepts named above. In accordance with the results of the analysis of metaphorical clusters in some contemporary novels, their thematic focus is thus classified as Anthropological, Social, Historical or Natural Focus.
\end{abstract}

Keywords: Cognitive approaches, contemporary literature, metaphor

\section{Introduction}

In this paper, we argue that the analysis of clusters of metaphorical use of language in a work of fiction, understood widely as all instances of figurative language use, can throw significant light on its subject and theme and can potentially contribute to the process of better understanding of imaginative prose by penetrating to the cognitive foundations of the linguistic choices made by the author.

The analysis of this kind is based on the identification of all textual stretches in which metaphorical constructions can be found and their analysis in terms of target - source relations seen as an extension of the traditional rhetorical approach, which utilizes the notions of the target and the vehicle and is employed in stylistics. Thus, we argue that depending on the pre-dominance of metaphorical modeling in a work of fiction, novels with four types of thematic focus can be singled out: one with an Anthropological focus, one with a Social Focus, one with a Historical focus and one with a focus on Nature.

The analysis has been conducted on the basis of a corpus of contemporary post-modernist novels in English from which metaphorical stretches of language use have been extracted. The novels under analysis were written in the period 1980-2006 and the corpus of textual stretches, which have been analyzed, equals 3,500.

The procedure employed for the investigation is further illuminated in this paper with the help of the analysis of metaphorical modeling in four contemporary novels seen as examples of meta-representational nature of contemporary literature: M.Amis' Night Train, M.Cunningham's The Hours , G. Swift's Waterland and J. Barns' The History of the World in $101 / 2$ Chapters. The analysis of metaphoric modeling in these novels helps to reveal their thematic focus and classify them as Anthropological (The Hours), Social (Night Train), Historical (Waterland) and Natural (The History of the World in $10 \mathrm{1} / 2$ Chapters). The procedure and the present paper is based on the assumption that works of fiction reflect the world view and the thinking processes of the author and which in their turn influence those of the reader (Zunshine 2006).

\section{Literature Review}

The present study is based on modern cognitive approaches in linguistics which see the metaphor as a basic mental operation as well as a means of understanding, structuring, evaluation and explanation of the world at large (Kovescez 2010, Lakoff and Johnson 1980). Under this approach, authors not only express their ideas through metaphors, using 
them to decorate the style, but they also think in metaphors, investigate and explain the world with the help of metaphors, and, in the process of communication, strive to transform the picture of the world existing in the mind of the listener/reader (Zunshine 2006).

Thus, the notion of metaphor in this approach is extended and includes not only the metaphor, but such methods of the transfer of meaning (figures of speech or tropes in stylistics) as metonymy, simile, oxymoron, periphrasis, double meaning, wordplay/pun, irony, hyperbole and litotes (Kovescez 2010). This expanded understanding allows the researcher to call any transfer of meaning from one object to another 'metaphor' on the basis of contiguity, similarity, analogy, free association and other techniques.

This idea, and the detailed examination of the underlying processes, was first extensively explored by George Lakoff and Mark Johnson in their work Metaphors We Live By (1980). Other cognitive linguists study notions similar to metaphor under the labels "analogy", "conceptual blending" and "ideasthesia".

Let us consider the following fragment from a novel by Margaret Atwood which describes a high school episode of teaching the T.Hardy's novel "Tess of d'Ubervilles":

\begin{abstract}
"She drove us briskly through the curriculum as if herding sheep, heading us off from false detours and perilous cliff edges, nipping at our heels when we slowed down in the wrong places, making us linger in the right ones so we could assimilate the material of importance. She described our task of learning as a race, a sort of obstacle course: there was a lot of ground still to be covered before the final exams, she said, and it had to be covered rapidly. The ground was strewn with hurdles and rough parts, and other difficulties. The days were speeding by, and we still had Tess of the d'Urbervilles looming up ahead of us like- we felt - a big steep hill of mud. It was true that once we got to the top of it, Miss Bessie - who'd been up there many times before - might show us a view; but meanwhile there would be a lot of slipperiness" (Atwood).
\end{abstract}

The highlighted fragments of the text are the cases of the meta-representational language use (McRae 1992), which, though classified differently in traditional stylistic approach, are all based on the transfer of meaning and can , in the words of Kovesces, be considered "an interrelated system of metaphoric elements which runs visibly through an entire work or a self-contained episode" (Kovesces 2010: 51-52). Such "megametaphors", running through a long passage or entire literary texts, ensure their metaphorical coherence by linking together "micrometaphors" found at the surface level of textual organization.

The idea of the literary text as an example of meta-representation is based on the contemporary approaches in the Theory of Mind, which study "representations of representations" (Sperber 2000). Literary texts in this approach are seen as utilizing "double encoding" as they use the linguistic material to create fictional worlds which is, in its turn, already based on the representational material of language used to describe linguistic reality.

Such approach to the study of literature is seen as the major contemporary development in the practice of literary study, as "the most recent linguistic approach to literature, which employs the theory of cognitive metaphor claiming that metaphor is not a mode of language, but a mode of thought" (Semino 2008). Such kind of work is seen as redefining the critical notion of imagery bridging together linguistics and literary theory: "Perhaps for this reason, cognitive metaphor has significant promise for some kind of rapprochement between linguistics and literary study" (Stockwell 2002:31).

\title{
3. Methodology and Empirical Data
}

The present study utilizes the methodology and procedures of the contemporary theory of conceptual or cognitive metaphor which is seen as understanding of one idea, or conceptual domain, in terms of another. A conceptual domain can be any coherent organization of human experience. The regularly emerging metaphors employed, for example, in literary works, appear to be perceptually based, and this has led to the hypothesis that the mapping between conceptual domains corresponds to neural mappings in the brain (Langacker 1987).

A primary assumption of the theory of conceptual metaphor is that metaphors are the matter of thought and not merely of language. This study is thus based on the working hypothesis that the selection and study of metaphorical elements in fiction as exemplified above will help to reveal deeper - cognitive - processes underlying the metaphorical modeling in the works of contemporary writers, their classification and categorization. By modeling we mean the process of forming a combined space of meaning that brings the commonality between objects and their attributes. Metaphorical modeling occurs in the minds of both the speaker/writer and the listener/ reader. In the latter case, there is a counter modeling as a combined space of the construction of meaning, without which the understanding of metaphor cannot be achieved (Kovescez 2010). Thus, the study of texts in this way can contribute to the more in-depth interpretation and understanding of the processes involved in the creation and comprehension of literature. 
Following the established tradition in cognitively oriented studies of language and literature, we distinguish two main roles for the conceptual domains deposited in conceptual metaphors:

- $\quad$ source domain: the conceptual domain from which metaphorical expressions are drawn (e.g. ARGUMENT IS WAR);

- target domain: the conceptual domain that is under comparison (e.g. ARGUMENT IS WAR).

Under this methodology, the systematic set of correspondences that exist between constituent elements of the source and the target domains is called a mapping. The description of a conceptual metaphor is thus the process of singling out the set of mappings that applies to a given source-target pairing. The same idea of mapping between the source and target domains is used to describe inferences and analogical reasoning.

Literature is often associated with the more extensive use of metaphorical use compared to everyday speech or academic communication. This view, however, is not supported by the modern corpus-based studies of the occurrence of metaphor in different types of discourse (Stefanowitch 2007). What happens in literature though is that the metaphors employed in this type of discourse are mostly novel metaphors created as a result of such mental operations as extending, elaboration, questioning, combining, etc.

The research project has been carried out since 2007 and aims to identify the dominant areas, sources and scope of the targets of metaphorical expansion in the world view presented in the fictional texts of British and American authors of the late $20^{\text {th }}$ - early $21^{\text {st }}$ centuries $(1980-2006)$ and describe the most active metaphorical models in the picture of the world as found in a number of modern writers, as well as draw conclusions about their relevance to their style.

The material for this kind of analysis is found in the novels of the following authors: M. Amis, I.McEwan, J. Barnes, P. Baker, J. Dawson, M. Cunningham, A. Hollinhurst, G. Swift, A. Carter, M. Atwood totaling more than 7,000 pages. All of them, might be classified as belonging to the post-modernist trend on contemporary literature (Head, 2002). To date, from the works of these authors about 3,500 metaphorical units have been extracted and analysed.

\section{Results and Discussion}

As a result of the study, we found that in the world view presented in the contemporary English novel, the most frequent, dominant, detailed and structured metaphors are those which contain such concepts as CIVILIZATION, NATURE, HUMAN BEING and HISTORY.

It is established that the concept NATURE serves in the contemporary English literary discourse as the main source of metaphorical modeling and is presented by 978 models in the existing database. The following textual segments may exemplify the model:

"And there's also the bad weather: Bad weather is the big police" (Amis);

"Nick thought about the old-fashioned name Lionel. Of course it was related to Leo, but Lionel was a little heraldic lion,

whereas Leo was a big live beast" (Hollinghurst)

"Or perhaps they did not cease to be water people. Perhaps they became amphibians." (Swift);

"Victoria had no sense of guilt. She had no sense at all. She was a round, golden pigeon who cooed" (Carter).

It is important to emphasize that our study points to the overwhelming use of natural phenomena as a source not a target of metaphorical modeling thus confirming the existing view the source of metaphorical modeling is often more abstract in nature compared to the target:

"The Crick brothers see the wide world - which is not a wondrous fable. The wide world is sinking, the waters are returning, the wide world is drowning in mud" (Swift);

"It rained for forty days and forty nights? Well, naturally it didn't - that would have been no more than a routine English summer" (Barnes);

"At this point we leave the harbour of facts for the high seas of rumour" (Barnes);

"One moment you bark, one moment you mew, one moment you wish to be wild, one moment you wish to be tame" (Barnes);

"The voices are back and the headache is approaching as surely as rain, the headache that will crush whatever is she and replace her with itself" (Cunningham).

The concept HUMAN BEING occurs in 790 models in our material and acts as both a source and target of the metaphorical expansion: 
"She (Virginia) has aged dramatically, just this year, as if a layer of air has leaked out from under her skin. She has grown craggy and worn. She's begun to look as if she's carved from very porous, gray-white marble" (Cunningham); "Richard told her, thirty years ago, that under her pirate-girl veneer lay all the makings of a good suburban wife, and now she is revealed to herself as meager spirit" (Cunningham).

In the first example, the changes in the appearance of the main character serve as a target of metaphorical modeling, while the second example, in which the metaphor consists of three elements (the so-called XYZ metaphor (Kovescez 2010)), human being serves both as the source and the target of metaphor construal.

The following examples also serve to exemplify the model aimed at representing different aspects of human physicality and psychology:

"When I was small I possessed a living image of my ancestors in the form of Bill Clay, a shrunken, leatherly carcass of a man, whose age was unknown, but was never put at less than eighty... who wore an otter-skin cap, eel-skin gaiters and whose brain was permanently crazed by the poppy-head tea he drank to ward of winter agues" (Swift);

"He (Jacob Crick) acquires the virtue, if virtue it is, of which the Cricks have always had good supply: Phlegm. A muddy, silty humour" (Swift);

"In old age, memory and imagination merge; Mrs Rundle's mental demarcations were already beginning to blur" (Carter);

"My features I inherited from my father. They are rural rather than urban - flat, undecided" (Amis).

The concept of HISTORY, presented by 630 models, also serves as a source and target of metaphorical modeling. The following examples can serve to illustrate the model:

"When news reached them at last, though they never went looking for it, that the Colonies had rebelled, and that there had been a Waterloo, a Crimea, they listened and repeated what they heard with wide-eyed awe, as if such things were not the stuff of fact but the fabric of wondrous tale " (Swift);

"But hold on, Lewis. Cutting back history? Cutting history? If you're going to sack me, then sack me, don't dismiss what I stand for. Don't banish my history"(Swift).

The concept of CIVILIZATION was found in 595 models and serves mostly as a target of metaphoric modeling. The foolowing textual stretches can exemplify this model:

"As far as the welfare of every other living form on earth was concerned, the human project was not just a failure, it was a mistake from the very beginning" (McEwan);

"American cities like to fix it so that their seats of learning surrounded by war zones (that is reality, pal) and it used to be that way around here. Ten years ago, Volstead Street was like the battle of Stalingrad" (Amis);

"Here is the ordinary world, a movie being shot, A Puerto Rican boy cranking open the awning of a restaurant with a silver pole." (Cunningham);

"Nick gazed out politely at the desert of digging and concrete, and beyond it a field where local boys were roaring round and round on dirt..." (Hollinghurst, 46);

"The Crick brothers see the wide world - which is not a wondrous fable. The wide world is sinking, the waters are returning, the wide world is drowning in mud" (Swift).

"Everything in the world is part of a vast, inscrutable intention and everything in the world has its own secrets name, a name that cannot be conveyed in language, but is simply the sight and feel of the thing itself." (Cunningham).

It was also found that the system of metaphors, represented by the basic concepts of the contemporary fictional discourse, provides an effective way of investigating the world view presented in these works of fiction and allows to discover the essence of the basic ideas of the author, and through this, makes it possible to re-create the fragments of the world view of the creator of the text through an analysis of selected concepts and metaphor as key means of their representation.

As part of the study of the literary discourse, the recurring metaphorical models, reflecting the process of thinking of the creators of the texts, included in the present study, can be regarded as leitmotifs - cross-level units of meaning.

Thus, we investigated M. Amis' novel Night Train, in which the metaphorical models containing the concept of CIVILIZATION, not only outnumber all the others, but are also the most detailed and thoroughly structured and include the largest number of frames. On this basis, as recognition of recurring patterns as the units of meaning creation (leitmotifs), the novel Night Train may be considered a novel with the socio-centric dominant theme.

The models containing the concept of HISTORY in G. Swift's novel Waterland are numerically superior to the other and represent the largest number of conceptual metaphors. Based on this, the novel is considered by us as the novel 
with the history-centric dominant theme.

The models containing the concept of HUMAN BEING in M. Cunningham's novel The Hours is numerically superior to the other and are also the most detailed and thoroughly structured and include the largest number of frames. On this basis, the novel The Hours is considered by us a novel with the dominant anthropocentric theme.

The study also revealed that the concept of NATURE in J.Barnes' novel The History of the world in $101 / 2$ Chapters can be classified as one with a focus on nature and thus having a natural theme. The metaphorical models identified in the course of the analysis of this novel may be said to present a metaphorical network which runs through the entire body of the novels and has Nature as the primary source of metaphorical modeling.

\section{Conclusion}

Our analysis has clearly demonstrated that the choice of metaphor is connected with the different value orientations of the authors and reflect different types of thinking (oriented towards humans, nature, modern society or history). Each authorial paradigm contains a number of key metaphors which contain a specific element of evaluative potential, which, in its turn, might be influenced by extra-textual societal factors. Metaphor is thus happens to be a widely distributed phenomenon that encompasses all reality presented in the works of contemporary fiction, making sense of literary discourse cannot take place without understanding the metaphorical models underlining the linguistic "surface" of the literary text.

The function of the metaphorical modeling we find in literary texts can thus be summarized as that of providing coherence for this type of discourse linking the fictional world of literature with the notions of HUMAN BEING, HISTORY, CIVILISATION and NATURE formed as a result of our real-life experiences. The metaphorical models uncovered as the result of the undertaken study have also pointed towards the existence of some intertextual coherence in contemporary fiction in English achieved though the employment of similar sources and targets of metaphorical modeling. This hypothesis though needs further investigation and presents a new goal for the continuation of the present study.

\section{References}

Head D. The Cambridge Introduction to Modern British Fiction, 1950-2000. Cambridge: CUP, 2002. - 350 p.

Kovesces, Z. Metaphor: A Practical Introduction. Second Edition- Oxford: OUP, $2010-370$ p.

Lakoff G., Johnson M. Metaphors We Live By - Chicago; L.: The Univ. of Chicago Press, 1980 - 212 p.

Langacker, R. Cognitive Grammar - New York: Oxford University Press,1987 - 367 p.

McRae, J. Wordsplay - L.: Mamillan Publishers, $1992-87$ p.

Semino E. Metaphor in Discourse - Cambridge: CUP, 2008 - 435 p.

Sperber, D. (ed) Metarepresentations: A Multidisciplinary Perspective - New York: Oxford University Press, 2000 - 1212 p.

Stefanowitch, A. (ed) Corpus-Based Approaches to Metaphor and Metonymy - Berlin: Mouton de Gruyter, 2007 - 674 p.

Stockwell, P. Cognitive Poetics - London: Routledge, 2002 - 212 p.

Zunshine, L. Why We Read Fiction: Theory of Mind and the Novel - Columbus: The Ohio State University Press, 2006 - 198 p. 